\title{
Is Loose Lower Wear Good for Sperm?
}

\author{
Rahul Hajare* \\ Indian Council of Medical Research, New Delhi, India
}

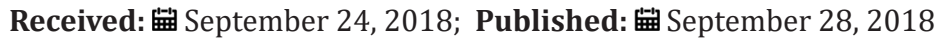

*Corresponding author: Rahul Hajare, Indian Council of Medical Research, New Delhi, India

\begin{abstract}
It has super important sperm and quality of sperm has critical windows into overall health and production of generation. Researcher wants to express this research to the people living with a healthy sperm counts life. Healthy sperm healthy generation. Number of male infertility treatments has available. It has many perceptions for infertility in men, women. In India 15 percent of couples are infertile. It had unconditional hormonal secretion has not capable to conceive a child even though they have had frequent, unprotected sexual intercourse for a year or longer. In up to half of these couples, male infertility plays a role. Overexposure to certain environmental elements such as heat, toxins and dried chemicals can reduce sperm production or sperm function. Industrial chemicals and sperm count have many reported researches underwent in globally. Extended exposure to benzenes, toluene, xylene, pesticides, herbicides, organic solvents, painting materials and lead may contribute to low sperm counts. Exposure to lead or other heavy metals also may cause infertility. Sparking the testicles due to cross connection. Elevated temperatures impair sperm production and function. Although studies are limited and are inconclusive, frequent use of saunas or hot tubs may temporarily impair sperm count. Sitting for long periods, wearing tight clothing or working on a laptop computer for long stretches of time also may increase the temperature in scrotum and may slightly reduce sperm production.
\end{abstract}

Keywords: Blue line jeans; black line jeans; dark blue line jeans; sperm

\section{Introduction}

As in many developing cities, in Pune infertility treatment is missing from available reproductive health services and lack of behavioral sense of humor. The Government of India's public health programme fails to address infertility even though the International Conference on Population and Development's (ICPD) programme of action $[1,2]$, to which the government is a signatory, states that reproductive health services should include prevention and appropriate treatment of infertility. While national policies and international donor organizations even today single - mindedly pursue programs to prevent unwanted pregnancies, they do little to address the needs of childless couples. Although the Indian government in its recent development and health policies has once again reiterated its commitment to the ICPD programme of action, and though the government's Ninth Five -Year Plan (1997-2002) document included infertility in its comprehensive reproductive and child health package, the primary health care system has been unable to convert this intent into reality and time has running out.

\section{Development of Research Methodology}

Men who most frequently wore blue line jeans had significantly higher sperm concentrations and total sperm counts, a study has revealed. Turns out, certain styles of men's lower wear may inhibit production of sperm. According to new research led by researcher of India, men who most frequently wore blue line jeans had significantly higher sperm concentrations and total sperm counts when compared with men who did not usually wear blue line jeans. "These results point to a relatively easy change that men can make when they and their partners are seeking to become pregnant." For this study, researchers collected information and semen samples from 656 reference and standard men who were part of couples that were seeking treatment at a fertility Centre. The men, who were between the ages of 32 and 39, completed a survey that included questions about the style of lower wear they wore in the previous three months. Options included blue line jeans, black line jeans, dark blue line jeans, briefs, and other. Men who wore blue line jeans also had higher percentages of motile sperm or sperm that are capable of moving through the female reproductive system and fertilizing an egg. The most significant difference in sperm concentration was seen between men who wore blue line jeans and men who wore black line jeans and briefs. In addition, analysis of blood samples collected from 304 of the study participants showed that men who wore blue line jeans had 14 percent lower levels of follicle stimulating hormone (FSH) compared with men who haven't wear blue line jeans. FSH is known to play an important role in male fertility and is associated with sperm production $[3,4]$. The simultaneous presence of lower sperm counts and higher FSH among men wearing tight-fitting lower wear suggests the presence 
of a compensatory mechanism. In that, the decreased sperm production among men in tighter lower wear signals the brain to boost production of hormones that stimulate the activity of the gonads to try to increase sperm production.

\section{Controversy}

Despite some fact-based understanding of fertility, traditional beliefs as well as misconceptions about "normal" fertility persisted in the study couples. Deep scientific data collection and awareness about the infertility research in world renowned fertility center on the one hand, there appears to be some degree of awareness about the fertile, the morphology of conception and other aspects of fertility among more than three - fourths of the men interviewed.

\section{Conclusion}

Management of safety and health of couples and effective service delivery in lifestyle can reduce the chances of low sperm counts and it has also seen that more attachment of self-esteem and power about superiority can cause infertility.

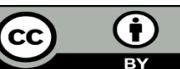

This work is licensed under Creative Commons Attribution 4.0 License

To Submit Your Article Click Here:

Submit Article

DOI: $10.32474 /$ IGWHC.2018.02.000148

\section{Acknowledgement}

We thank newly married couples as well as older couples and their family members of Pune region for comments and participate without any hesitation. This study has been guided by under supervision and guidance of Renowned Laboratory Scientist Respected Dr. Ramesh Paranjape' Retd. Director and Scientist 'G' National AIDS Research Institute India. I express my sincere gratitude towards Respected Sir' for motivation and being great knowledge source for this research.

\section{References}

1. World Health Organization (1980) Special Programme of Research, Development and Research Training in Human Reproduction. Ninth annual report. World Health Organization, Geneva, Switzerland.

2. (1983) Report of the meeting on the prevention of infertility at the primary health care level. Popline, k4Health, Genevva, Switzerland, p. $12-16$

3. Greiz AL (1997) Infertility and psychological distress: a critical review of the literature. Social Science \& Medicne 45(11): 679 -1704.

4. Friday Okonofua, Datta B (2002) What About Us? Bringing Infertility into Reproductive Health Care. New York Population Council, Quality Publications, USA.

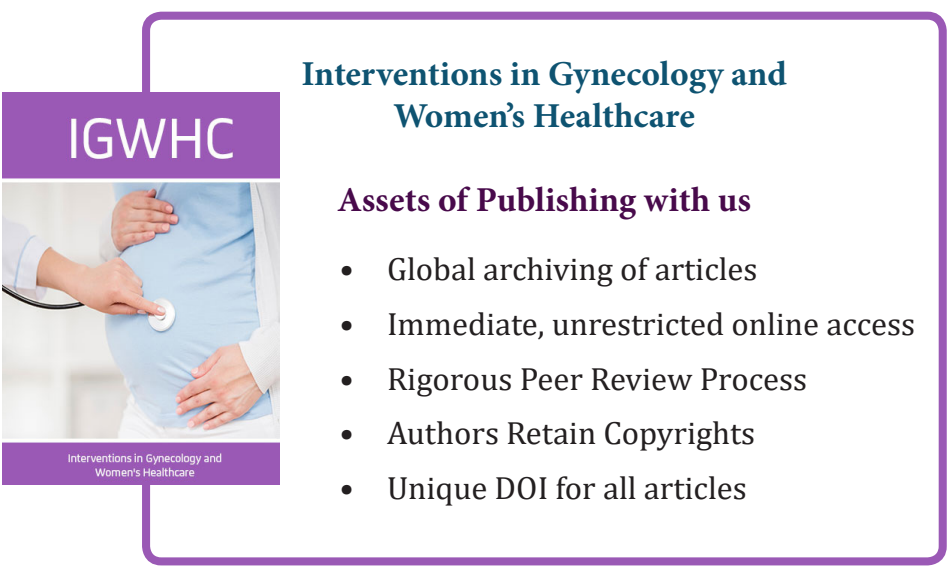

